\title{
Mapping land use impact of photovoltaic farms via crowdsourcing in the Province of Lecce (Southeastern Italy)
}

\author{
G. Mauro ${ }^{\mathrm{a}, *}$, V. Lughi $^{\mathrm{b}}$ \\ ${ }^{a}$ Department of Humanities, GISLab, University of Trieste, via Tigor, 22, 34124 Trieste, Italy \\ ${ }^{\mathrm{b}}$ Department of Engineering and Architecture, Laboratory for Nanotechnologies and Photovoltaics, University of Trieste, Via A. Valerio, 6/A, 34127 Trieste, Italy
}

\section{A R T I C L E I N F O}

\section{Article history:}

Received 23 November 2016

Received in revised form 25 May 2017

Accepted 13 June 2017

\section{Keywords:}

Photovoltaic farms

OpenStreetMap

GIS

Land take

PV plants geographical distribution

\begin{abstract}
A B S T R A C T
Photovoltaics (PV) is the fastest-growing renewable energy source at the global level and Italy has been one of the pioneers of such growth, now being one of the Countries with the largest installed PV capacity - absolute, per unit area, and per capita. In this paper we investigated the impact of PV on land use in the area with the highest density of PV farms in Italy, i.e. the Province of Lecce (Southeastern Italy): here, such impact is expected to be maximum and has been the subject of public debate. In order to map all PV farms in detail, we used participative cartography, specifically OpenStreetMap (OSM), as data source. This international project collects geographic information (often gathered by people - i.e. the so-called Volunteered Geographic Information, VGI - using widely available technologies, such as smartphone built-in GPS), in order to create freely available global topographic maps. In this paper, we used the OSM platform to create a Geographical Information System (GIS) of PV farms in the Province of Lecce. Using GIS-based techniques, we estimated land use at the municipality level and created a density map of PV farms within the study area. Using the official land cover map Corine Land Cover of 2012 , we also evaluated the main changes in land use. The results highlight the correlation between spatial distribution of PV farms and geographic variables (geomorphology, demographics, tourism, etc). We also show that land take by PV farms is quite marginal even in a region such as the Province of Lecce, where the density of PV installed power is among the highest available at the global level.
\end{abstract}

(c) 2017 Elsevier Ltd. All rights reserved.

\section{Introduction}

In Italy, the share of Renewable Energy Sources (RES) in total energy consumption was $17.1 \%$ in 2014 and $17.5 \%$ in 2015 (GSE, 2017). The national 2020 target is set at $17 \%$, but at present it is still largely covered by hydropower, and therefore depends on climatic fluctuations (Pacesila et al., 2016; Spalatro and Nicoletti, 2014). However, over the past few years, solar photovoltaics (PV) in Italy has become one of the major actors in the electric power portfolio.

The recent fast growth of PV in Italy has been due to rooftop installations and building integrated PV or other minor plants, but most of all to large PV farms, which account for more than $40 \%$ of the total PV installed capacity. This has often been associated with a supposedly marked transformation of the landscape due to several kinds of impact (Chiabrando et al., 2009): land use, reduction of cultivable land, fragmentation of the countryside,

\footnotetext{
* Corresponding author.

E-mail address: gmauro@units.it (G. Mauro).
}

plant degradation, visual impact on the landscape, interference with fauna and flora, microclimate change, glare, and impact associated with the construction phase. However, the impact per unit area of these ground-mounted large PV arrays on agricultural land is considered to be less significant compared to other electricity energy generation technologies, as vegetation can still grow in the area occupied by the PV plant, and animal grazing or in some cases agricultural activities are still possible (i.e., Dinesh and Pearce, 2016). On the other hand, solar parks are characterized by a low power density: PV panels are usually installed in parallel rows to avoid reciprocal shadowing, so that land occupation is quite relevant, about $25 \mathrm{~m}^{2} / \mathrm{kW}$ (Coiante, 2008). Estimates of the total area occupied by solar PV parks show a growing trend [33 km² in 2008 (Frascarelli and Ciliberti, 2011), almost $140 \mathrm{~km}^{2}$ in 2014 (GSE, 2016)], but such area remains a very little portion with respect to the Italian agricultural land area [about $128,850 \mathrm{~km}^{2}$ (ISTAT, 2011)].

The European Environment Agency (EEA) points out how land take due to the expansion of residential areas and construction sites is threatening agricultural zones and, to a lesser extent, 
forests and semi-natural and natural areas, which are decreasing in favour of the development of artificial surfaces. In the 2000-2006 period the annual land take in 36 European countries was 111,788 ha/year, mainly concerning arable land, permanent crops and pastures (EEA, 2008). In particular, land take in Italy is an environmental emergency: in just sixty years it has more than doubled, from $8100 \mathrm{~km}^{2}$ in 1950 to $21,000 \mathrm{~km}^{2}$ in 2014 (ISPRA, 2014). For these reasons, new soil occupation has become quite a delicate issue - even when it involves RES, such as new solar arrays, wind turbines or biomass crops.

Of course, there are many other issues regarding the impact of RES: to this regard Wüstenhagen et al. (2007) point out the three dimensions of social acceptance for renewable energy deployment (socio-political, community, and market acceptance). In detail, "community acceptance refers to the specific acceptance of siting decisions and renewable energy projects by local stakeholders". Therefore, it is very important to analyze permanent impacts of PV farms, such as land take and visual impact. Tsoutsos et al. (2005) underline how an optimal architectural solution can minimize potential impact on visual amenity. In order to quantify the visual impacts of solar parks, Torres-Sibille et al. (2009) proposed an Objective Aesthetic Impact (OAI) tool to assess the effects of a PV farm project before the regulatory authorization step. On the other hand, Zoellner et al. (2008), in a case study in Germany, point out how the most meaningful criteria for building new solar parks are economic parameters (as estimated costs and benefits of RES). Moreover, the PV industry can be a great opportunity in terms of jobs creation: in 2014, the PV sector employed 120,000 people in the EU (Observ'Er, 2015). Concerning the case of Italy, the PV and wind industries employ at least 40,000 people (Observ'Er, $2015^{1}$ ); also, since about 35\% of the RES power is installed in Southern Italy, the employment opportunity offered by the RES industry is expected to benefit in particular this economically depressed area. Nevertheless, there are critical aspects that partially offset the social benefits: for example, the lack of clarity of the bureaucratic procedures, or the delay in smart grids development, tend to lead to a higher cost of energy with respect to the European average, mainly for the small and medium enterprises of Southern Italy (SRMSVIMEZ, 2011).

In this paper we study the Province of Lecce (Puglia Region), which ranks first in Italy for the density of PV farms, both in terms of number and of installed capacity (GSE, 2016). At the moment no official digital cartography is freely available about this kind of land use. A large-scale map of PV farms could be an opportunity to study land transformation or potential land use conflicts among existing land-based economies and ecosystem services (Calvert and Mabee, 2015).

In recent years several technological innovations have profoundly changed the map production process, leading to the concept of 'crowdsourcing geographic knowledge' (Sui et al., 2013). Since the early 2000s, web mapping has become very popular on the Internet, mainly by means of a new set of cloud-based mapping tools, allowing for very advanced forms of mapping (Peterson, 2014). So, the geospatial data are often collected by people, taking part in the generation of Volunteered Geographic Information (VGI), as coined by Goodchild (Goodchild, 2007). Any citizen can easily determine location accurately, simply using a GPS, or find the position through an Internet web mapping service (e.g. Google Maps). So, through the use of ubiquitous technology such as smartphone built-in GPS, any citizen - even if not expert - can create maps in different fields of application such as, for instance, tourism, commercial uses and natural or anthropogenic risk assessment (e.g. the

${ }^{1}$ Observ'Er estimate 10,000 in PV sector and 30,000 in wind sector in 2014 (Observ'Er, 2015). case of Hurricane Katrina in September 2005) (Goodchild and Glennon, 2010). This is the 'revenge of geography' where 'in an increasingly connected world, the location, and more broadly geography, has assumed a more crucial role in economic and business activities as well as in social and cultural affairs (...)' (Sui et al., 2013).

In this framework, one of the most popular VGI-platforms is OpenStreetMap (OSM), the international project started in the UK in August 2004 and developed in order to create and provide free global topographic maps (Bennet, 2010; Ramm et al., 2011). However, if at the beginning VGI was mainly focused on road network data, now the attention has shifted to other features, such as buildings or land use (i.e., Neis and Zielstra, 2014). Now VGI of OSM maps PV farms, too, using a specific tag (cf. Section 6.1); therefore, it is possible to automatically extract the area of the land covered by PV farms by using Geographical Information System (GIS) software (i.e., Borrough, 1990) such as, for example, QuantumGIS.

Frequently, GIS applications are used to estimate the photovoltaic potential at different geographic scales, by using satellite images (i.e., Viana et al., 2011) or heterogeneous cartographic data (i.e. Choi et al., 2011; Colmenar-Santos et al., 2016). Conversely, the main goal of this paper is to evaluate land take impact of PV farms in the Province of Lecce, trough the creation of a detailed GIS mainly using OSM as source data. To assess its reliability, cartographic results are compared, at the municipality level, with the official data of the state-owned company which manages and monitors RES in Italy ("Gestore dei Servizi Energetici", GSE). Several pieces of information can be extracted from this map, such as for instance estimates of land take (discerning land cover class, too) due to PV farms.

The remainder of this paper is structured as follows: the next section is a brief introduction to participative cartography and OpenStreetMap. Section 3 outlines the status of solar PV in Italy, justifying the choice of this Country as a meaningful case study. Section 4 describes the area studied in this work, i.e. the Province of Lecce in Southeastern Italy. Section 5 refers to data sources. Section 6 presents the research methodology. Section 7 discusses the results. Section 8 collects some final remarks and conclusions.

\section{Participative cartography: the case of OpenStreetMap}

In the framework of Web2.0, the OpenStreetMap (OSM) project was started in 2004 with the main goal of building a free geographic database of the world. The map is free available from the main website of the project, www.openstreetmap.org. Crowdsourcing mostly involve VGI provided by common citizens during their spare time, but commercial organizations and governmental bodies are currently collaborating, too, to the achievement of the goals of this project (Bennet, 2010). In marked contrast to the main providers of proprietary data such as Google, Nokia or Microsoft, the OSM dataset is available under the Open Data Commons Open Database License, so users can freely access, modify and download the map. In a few years, this project has grown exponentially: at the time of writing, it had more than 3 million registered members, who contributed for almost 5.5 billion of GPS points (OpenStreetMap statistics, http://www.openstreetmap.org/stats/data_stats. html, accessed on October 30, 2016).

Active users (approximately 1\%) modify the OSM PostgreSQL database, mapping point information (represented by node objects) or lines and polygons (represented by way objects). In OSM the attribute information of each object is referred to as 'tag'. It consists of a 'key' and 'values' used to store metadata: the first describes a broad class of features (e.g., building, highway, landuse, ect.), the second details the specific feature that was generally classified by the key (e.g., for building = apartment). Finally, 
relations are sometimes used to explain a relationship between node and way (Ramm et al., 2011).

Whereas initially VGIs used to modify the map mainly using collected GPS tracks, from 2007 several companies (i.e., Yahoo! Aerial Imagery) started providing their satellite and aerial images to the project, as background for manual editing (http://wiki.openstreetmap.org/wiki/Vertical_Aerial_Photographs, accessed on September 20, 2016). In addition to contributes of registered users, several government agencies have released their official data to the OSM project. For instance, in Italy, from 2008 much of these data has come from the regional cartographic departments (Salvador, 2010), giving a significant impulse to the improvement of the OSM map of this Country.

The collected data are freely available for download. The complete dump is retrievable at planet.osm, where a new and complete copy of all data of OSM is available every week. Other websites, such as Geofabrick, provide daily updated data downloads, where it is possible to specify the geographic region in a hierarchical way (i.e., Europe $>$ Italy $>$ South).

The main strengths underpinning the success of this VGIplatform are a free and constantly updated map. However, quality assessment is still one of the most important critical issues of OSM, representing a key issue of the OSM Community, often investigated in many studies. For example, several researchers compare the road network obtained from OSM VGI versus the proprietary (i.e., Zieltra and Hocmair, 2011) or governmental cartography (i.e. Kounadi, 2009; Mauro, 2011). These studies often point out the high quality of the crowdsourced map. Other authors (i.e., Cipeluch et al., 2010) overlay OSM cartography to the main desktop web mapping services, like Google Maps or Bing Maps, revealing the abundance of detail in OSM. On these basis, several recent studies (i.e., Ribeiro and Fonte, 2015; Brian and Kotaro, 2016) report about the opportunity to use OSM in order to create Land Cover Maps.

\section{The recent growth of PV plants in Italy}

Photovoltaics is the fastest growing renewable energy technology at the global level, with more than 50 additional GW-peak installed in 2015 , corresponding to a $+25 \%$ growth on new installations with respect to 2014 (IEA, 2016). The global installed PV capacity reached over 227 GWp in 2015, providing about $1.3 \%$ of the global electricity generation. Such rapid - and formerly unexpected - growth was initially led by Germany, where pioneering feed-in tariffs triggered an astounding growth in the mid 2000s; Germany's PV cumulated power reached 39.7 GWp in 2015, at that time a number only surpassed by China with $43.5 \mathrm{GWp}$. Italy followed shortly after Germany as one of the pioneering Countries in $\mathrm{PV}$, introducing a bold feed-in tariff scheme ("conto energia") in 2005, which made Italy the world leading market in 2011 with the largest amount of new PV power installed in that year (about 9.4 GWp). Since then, the growth of PV in Italy has slowed down following the end of the incentives (mainly because of a diffused although unjustified perception that the economic competitiveness has suffered) while growth in other Countries such as Japan, China and more recently the U.S.A. has picked up, continuing the rapid expansion of the PV market at the global level. These are now the world leading markets, with an overall new PV power addition of $33.5 \mathrm{GWp}$ in 2015.

Italy is an interesting case of study (Fig. 1), as it is one of the pioneering Countries in PV, still the fifth Country at the global level in terms of cumulative installations $(18,910 \mathrm{GWp})$, and the global leader in terms of fraction of the national electricity final consumption covered by PV (over $7.2 \%$ in 2015 , corresponding to 22,847
GWh of electricity produced by PV). Moreover, Italy still ranks third in terms of installed power per surface area and second in terms of installed power per capita. This market explosion in Italy has been an important factor contributing to the dramatic price reduction at the global level of PV modules as well as of other PV-specific components of the BoS ("Balance of System", which encompasses all upfront costs associated with a PV system, other than the PV module), such as the power conditioning systems. At the Italian level, the market expansion also led to the acquisition of best practices and the consequent reduction of all costs and overheads associated with the realization of turnkey PV plants (ES, 2014) - such as engineering, labor, permitting, supply chain, etc. The simultaneous effect of global PV price reduction and national BoS reduction drove a dramatic drop of the overall turnkey price of PV plants in Italy over the past few years (from 2700 $€ / \mathrm{kWp}$ in 2010 to $900 € / \mathrm{kWp}$ in 2013 for large-scale PV parks; $E S, 2014)$. Because of the high end-user price of electricity at the national level, combined with the low cost of PV plants, Italy has been one of the first Countries to stably reach the grid parity regime (Pauli et al., 2015), whereby the cost of electricity from PV (measured as LCOE, Levelized Cost of Electricity) is equal or less than the end-user price of the electricity sold by the utilities. Interestingly, most of the extremely fast growth between 2010 and 2013 was due to large-scale PV plants, mostly concentrated in Southern Italy where more solar irradiation is available and large amounts of suitable land were available. The Province of Lecce, further analyzed in the following paragraph, is an especially representative case.

\section{The study area: the Province of Lecce}

The Province of Lecce (Puglia region) is the easternmost province of Italy (Fig. 2A), includes almost one hundred municipalities, and covers a total area of about 2760 square $\mathrm{km}$. It is part of Sale$n t o$, the geographical region including the entire Province of Lecce, a large part of the Province of Brindisi and part of that of Taranto.

The Province of Lecce is mainly a flat limestone plateau, named Tavoliere salentino; in the southern region there are some hills, named Serre salentine (Fig. 2B). They are alignments of small rocky crests (the highest point is Serra dei Cianci, $201 \mathrm{~m}$ ), descending towards the eastern coast directly to the sea or through cultivated terraces. Warm temperature during the Summer and mild temperature in the Winter characterize the climate of the Province of Lecce (Sestini, 1963).

In order to assess the impact of PV on the rural landscape and the primary sector, it is important to observe that the most recent Italian agricultural Census (2010) highlighted a marked decrease of Utilized Agricultural Areas in the Province of Lecce over the last forty years $(181,244 \mathrm{Ha}$ in 1982; 161,130 Ha in 2010), in agreement with the national trend. Although over the same period the number of farms slightly increased $(68,415$ in $1982 ; 71,060$ in 2010), their average size $(2.3 \mathrm{Ha} / \mathrm{farm})$ is small, below the national average (7.9 Ha/farm). Cereals (31.2\%, mainly wheat) and olives (60.4\%) are the main crops, but they have shown opposite trends in the last ten years: while cereal production decreased $(-2.5 \%)$, the cultivation of olive trees has rapidly grown $(+16 \%)$, and now the Province of Lecce is the first in Italy for this kind of production (ISTAT, 2011).

Finally, concerning PV, in 2015 the Province of Lecce ranks first in Italy for number of installations (14,332), for the cumulated installed PV power (681 MW of 18,892 in Italy) and for PV energy production $(973,9 \mathrm{GWh}$, i.e. $4.4 \%$ of the national production) (GSE, 2016). This is the main reason for choosing this Province as an exemplifying study area to analyse impacts and benefits of PV farms on a rural region. 


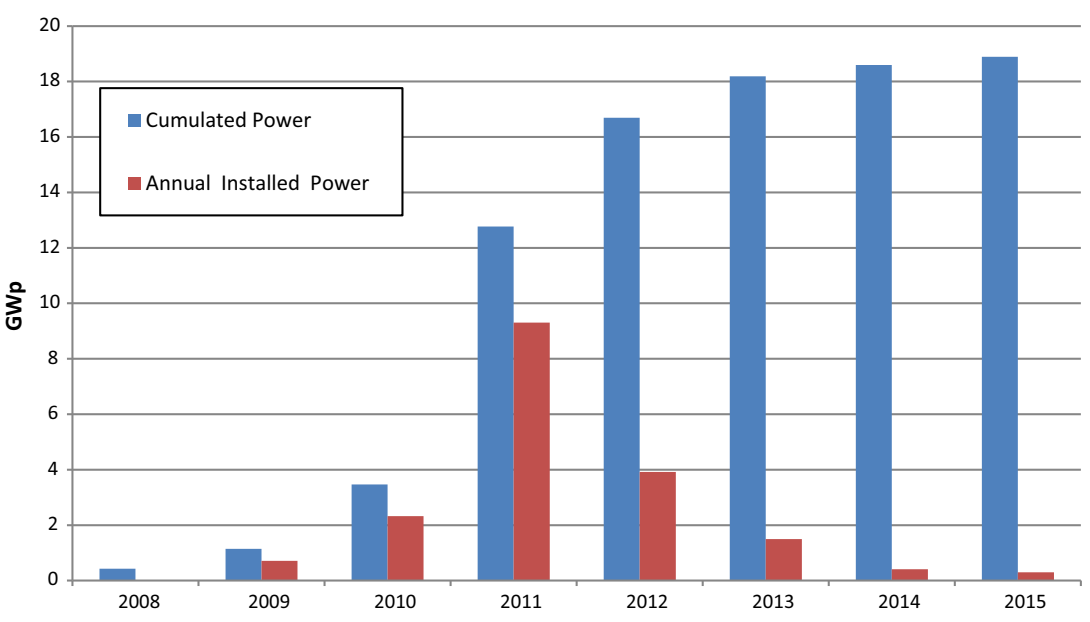

Fig. 1. Recent evolution of photovoltaics in Italy (data source: GSE, 2016).
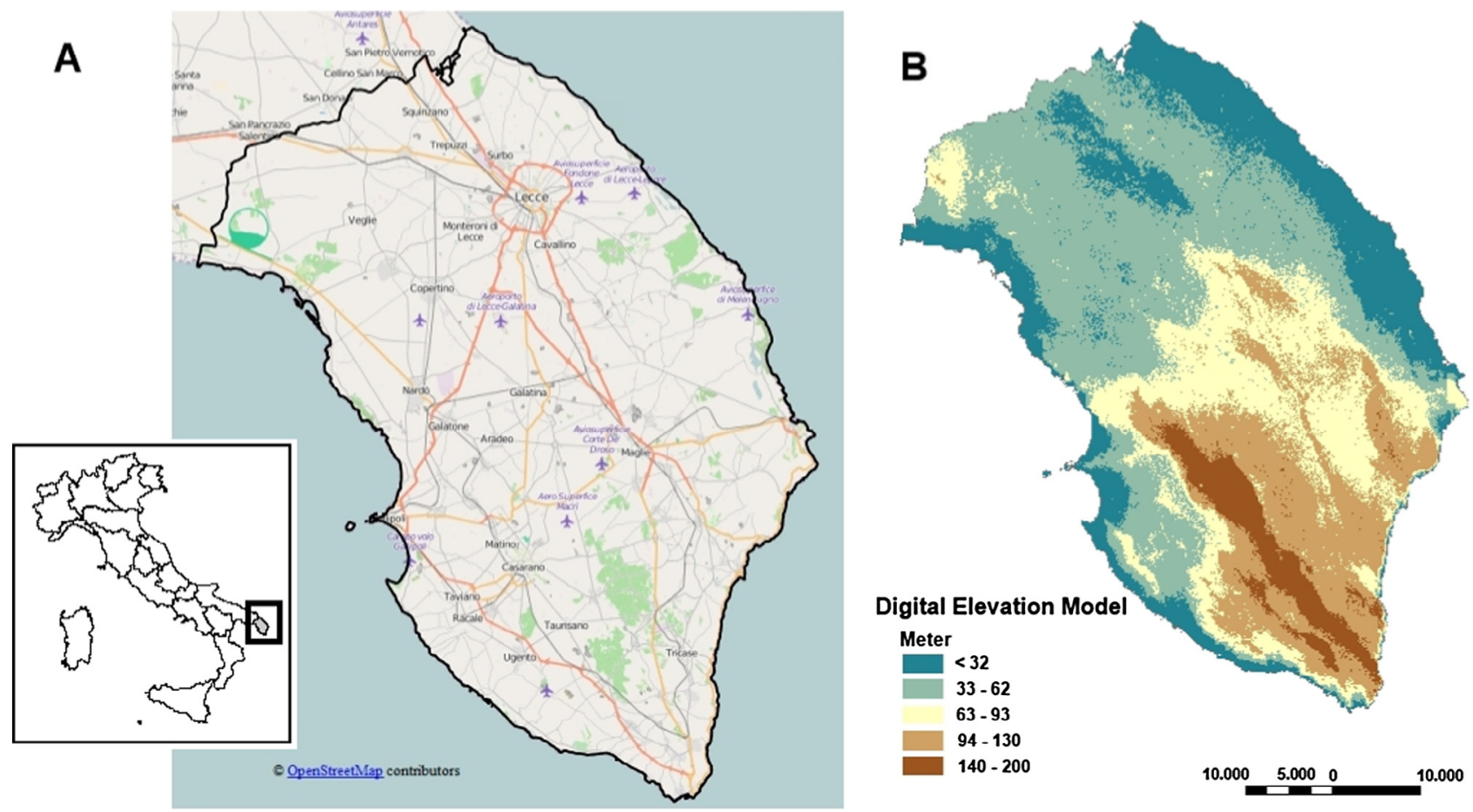

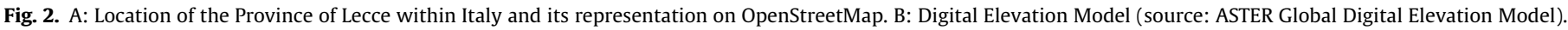

\section{Data sources}

We use several data sources in order to map in detail the PV farms of the Province of Lecce.

First, we considered OSM. As previously suggested (cf. Section 2), it is possible to download the OSM dataset in many ways (Ramm et al., 2011): there are several mirror sites where the user can download the cartography for the entire planet, for a single Country or for several regions of the world. Also, the user can download data directly from the OSM main site. The user can select a small area and, using the export tab, he can obtain the OSM data in XML format or as an image (jpg format). In order to achieve our purposes, we downloaded (January 2016) the OSM data defining our study.

For the PV installed power, we used the official data of the stateowned company managing and monitoring RES in Italy, the Gestore dei Servizi Elettrici (GSE). Transposing the National legislation about RES monitoring (Legislative Decree n.28/2011), GSE created a webGIS (a web map on the World Wide Web) named Atlasole (http:// atlasole.gse.it/atlasole/, accessed on September 14, 2016), very useful for visually and quantitatively monitoring the overall PV state in Italy. Using this webGIS, one can easily map the number and power of PV installations at several administrative levels (region, province or municipality). A classification of all PV plants by installed capacity is also available $(1-3 \mathrm{~kW}, 3-20 \mathrm{~kW}, 20-$ $200 \mathrm{~kW}, \quad 200-1000 \mathrm{~kW}, \quad 1000-5000 \mathrm{~kW}$ and higher than $5000 \mathrm{~kW}$ ). Finally, it is possible to download detailed data of a selected study area. For our purposes, we acquired the PV state of all the municipality in the Province of Lecce on January 31st, 2016.

In order to assess land take due to PV and classified by land cover, we use the cartography of CORINE Land Cover (CLC). CORINE 
(acronym of COoRdination of Information on the Environment) Land Cover is an international project working since 1985 on many different environmental issues. One of the main features is "an inventory of land cover in 44 classes, and presented as a cartographic product, at a scale of $1: 100,000$, available for most areas of Europe" (EEA, 1995). In particular, we considered the third level of classification CLC data, updated to 2012: this level narrows down to a very specific characterization. For example, agricultural areas is a first level of classification (coded 2), permanent crops is second level (coded 2.2), while olive groves is third level (coded 2.2.3).

In summary, we used: (1) OSM as main data source to create PV-GIS of Lecce; (2) the GSE data in order to obtain detailed PV power and PV energy production data; (3) the CLC to evaluate the land take in each land cover class.

\section{Method}

The research method is illustrated in Fig. 3. From the OSM dataset, we created the GIS of PV farms in the Province of Lecce (named as PV-GIS Lecce) after several detailed controls - in particular, extensive visual interpretation monitoring and comparison with the GSE data (cf. Section 6.1).

After validation of the PV-GIS Lecce vector layer, we used it for several purposes.

First, we estimated land take at the municipality level: we considered the total area of PV farms within each municipality and we calculated its incidence rate (as thousandths).

Based on the PV-GIS Lecce vector layer, we also created the density map of PV farms in the study area, in order to better understand their geographical distribution.

Then, we evaluated the loss of soil for all significant land use classes. Using GIS, we overlaid PV-GIS Lecce to the CLC cartography and automatically extracted, using the crop tool, areas in which PV farms have been built.

In the following paragraphs, we report the methodology in detail.

\subsection{From OSM dataset to the PV-GIS of Lecce}

OSM is our main data source for mapping PV power installations as accurately as possible.

In the OSM map, the attribute information of each object is referred to as tag (cf. Section 2). So, for our purposes we analyzed the group of tags referring to 'power = generator': 'generator:source = ', 'generator:method = ' and 'generator:type = '. This group describes a device converting one kind of energy to another. The first combinations identify the 'energy source' for the generator (e.g., oil, wind, biomass, nuclear, etc.); the second classifies the 'technical method or process' that converts the source in energy output (e.g., combustion for coal, wind turbine for wind, fusion or fission for nuclear, etc.); the third defines the specific type of generator (e.g., for wind energy, wind turbine with horizontal or vertical axis). ${ }^{2}$

In this paper, we consider only PV farms: the source of generator is 'solar', the method is 'photovoltaic' and the type is 'solar photovoltaic panel'. If the VGI would like to modify OSM, map editors are available (i.e., iD OSM map editor) providing a user-friendly tagging mask (Fig. 4). Registered users can easily identify a PV farm on the satellite images by visual image interpretation: color, size, shape, texture, pattern, high, shadow, location and context are all basic visual image elements that help understanding the type of feature present on the ground (land cover) (Lillesand and Kiefer,

\footnotetext{
${ }^{2}$ OSM Wiki, Generator Tag, http://wiki.openstreetmap.org/wiki/Tag:power\%3D-
} generator (accessed on July 15, 2016).

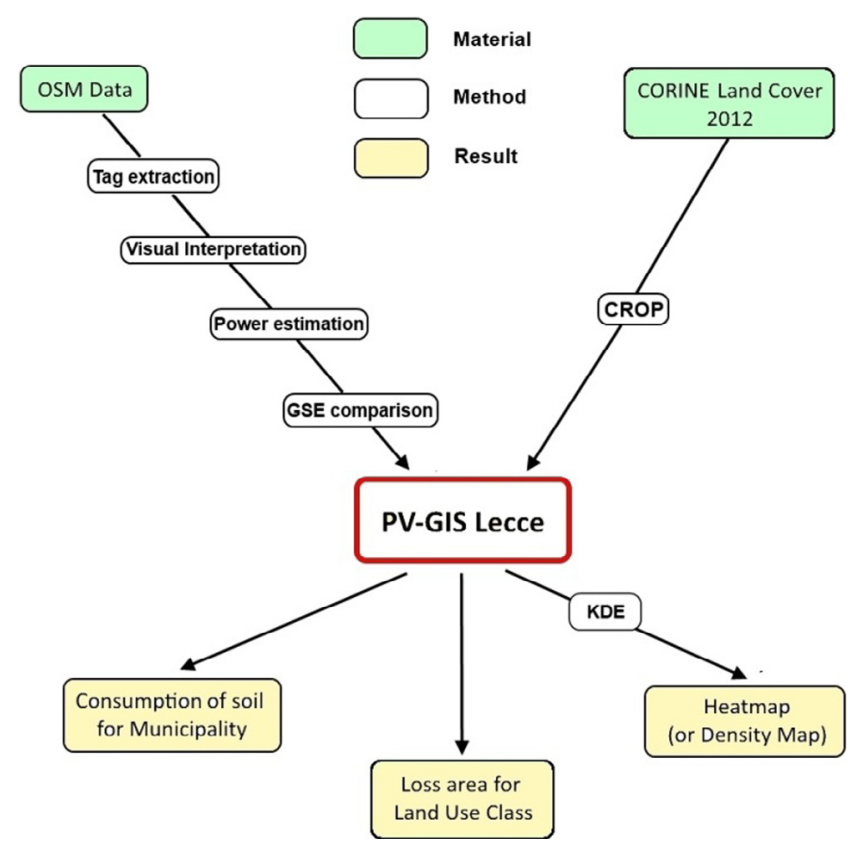

Fig. 3. The methodology scheme.

2000). It is very easy to recognize the PV power installations because the solar array is aligned along parallel bands, showing a very regular texture (Fig. 4). So, using the map editor, the VGI inserts a new polygon in the OSM and all the known metadata (i.e., solar as source, photovoltaic as method, etc.), by means of the group of tags described above.

In this work, we downloaded the OSM vector layer and imported it in an open-source GIS software, Quantum GIS (QGIS). Selecting the specific tag (concerning 'generator'), we choose the typology of data (polygon) to import and convert to a more general cartographic format (i.e. shapefile). In this way we created the first PV-GIS.

The next step was a careful monitoring of this cartographic result. We overlaid our first map on the updated aerial or satellite images (also available in QGIS) at a medium scale (1:25.000). In this way, we easily identified missing PV farms. So, we assess the overall accuracy of the original OSM data: this datasource covers most (more than $80 \%$ ) of the existing PV farms. This gap is mainly due to incorrect tag assignment by VGI. ${ }^{3}$ At the same time, we integrated the first PV-GIS, adding the specific typology to each PV farm: by visual interpretation we recognized the solar array arrangement (fixed or tracking). This represent an evolution of the previous PVGIS. We named this new cartographic map "PV-GIS Lecce" (Fig. 3).

However, in order to validate our cartographic results we need to estimate the installed power at the municipality level, because the official GSE data report only this kind of information. Therefore,

\footnotetext{
${ }^{3}$ There are two main problems in such research. The first is the limit of download: from OSM the user have to define an area smaller than 0.25 degree in either dimension (http://wiki.openstreetmap.org/wiki/Downloading_data; accessed on March 28, 2016). Also if it is possible to obtain OSM data for larger area from several mirrors like Geofabrick (as pointed out in Section 2), this kind of maps are more 'generic': they do not provide detailed cartographic information such as, for example, PV farms. The second limit is a OSM "coding problem": sometimes, when users insert a new polygon associated to a PV farm, they identify this kind of land use in several ways (i.e., generic 'area' or 'power plant') and not with the formal tag. Therefore, it could be problematic to automatically extract them in a GIS. It is therefore very important to pay attention to this step, in order to warrant an overall good quality of work. In some cases, this step can be quite time consuming. However, in this study the high quality of the native data source (covering about $80 \%$ of existing PV farms) greatly reduced the processing time of this step.
} 


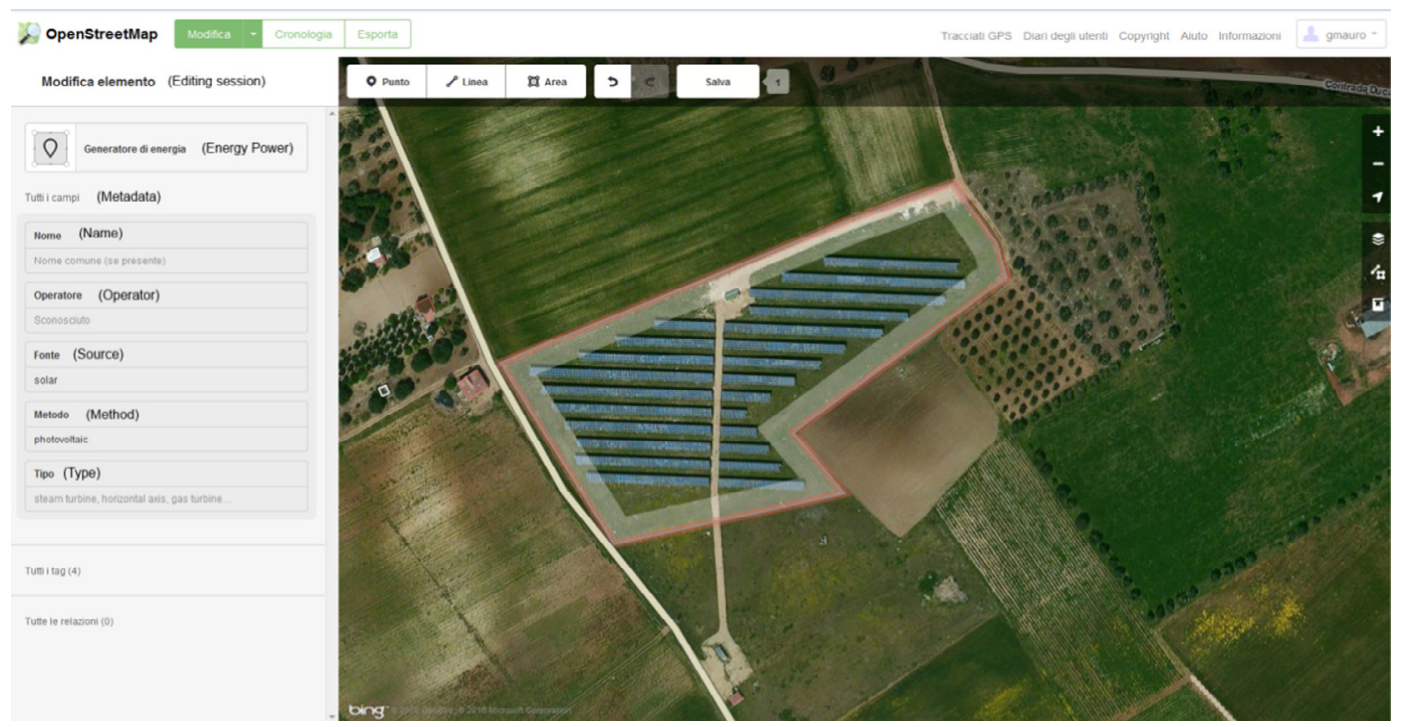

Fig. 4. A PV farm with fixed solar array arrangement on the satellite image visualized with iD OSM map editor. On the left, the tagging mask.

we first automatically extracted the area for each PV farm, using GIS tools. Then, applying the algorithm and parameters described in paragraph 6.2, we estimated the associated installed power. Finally, we overlaid the administrative vector layer and automatically extracted the cumulated power value for each municipality. With regard to the GSE data, we considered only the PV plants with power larger than $200 \mathrm{~kW}$, in order to avoid confusion with smallsize PV installations (such as rooftop PV plants). Finally, these selected GSE data were compared to the data obtained from the PV-GIS Lecce.

Once validated the PV-GIS Lecce, we created a density map in order to better evaluate the spatial distribution of PV farms within the Province of Lecce. Applying a Kernel Density Estimation (KDE), heat maps show where the highest concentration of features is (Michell, 1999). Generally, it is more useful to look at patterns rather than at the location of individual features. Frequently used in point pattern analysis (Cressie and Wikle, 2011), KDE is a nonparametric method that allows evaluating the probability density function of a random variable (Silverman, 1986). Recently, several authors (i.e. Danese et al., 2008) point out also its spatial application both in a homogeneous region (Chainey and Ratcliffe, 2013) and in an anisotropic space (influenced, for example, by a road network; Delmelle et al., 2014). In accord to the literature, we focused on radius choice (i.e., Hart and Zandbergen, 2014), cell size (i.e. Danese et al., 2008) and KDE function (i.e., Borruso, 2008).

In this paper we considered the spatial distribution of point features, where each point is the centroid of the PV-GIS Lecce vector layer. These point features are automatically extracted from the layer of the detected PV power stations. Each point represents a single power station, as well as its area (square meters), properly weighted in the KDE analysis. Considering the size of the study area (about $2760 \mathrm{~km}^{2}$ ), the average distance between PV farms (about $26.1 \mathrm{~km}$ ) evaluated using a distance matrix, the average size of PV farms (about $27,700 \mathrm{~m}^{2}$ ) and, finally, the cell size $(150 \mathrm{~m}$; $22,500 \mathrm{~m}^{2}$ ), we set a search radius of $4000 \mathrm{~m}$. We choose the quartic kernel as KDE function (Silverman, 1986). The result is shown in Fig. 7B, i.e. the area of PV per cell in $\mathrm{m}^{2} /$ cell units.

\subsection{Estimates of power and annual energy production of the plants}

One key criterion for classifying photovoltaic plants is peak power, i.e. the power that the plant can generate at Standard Test-

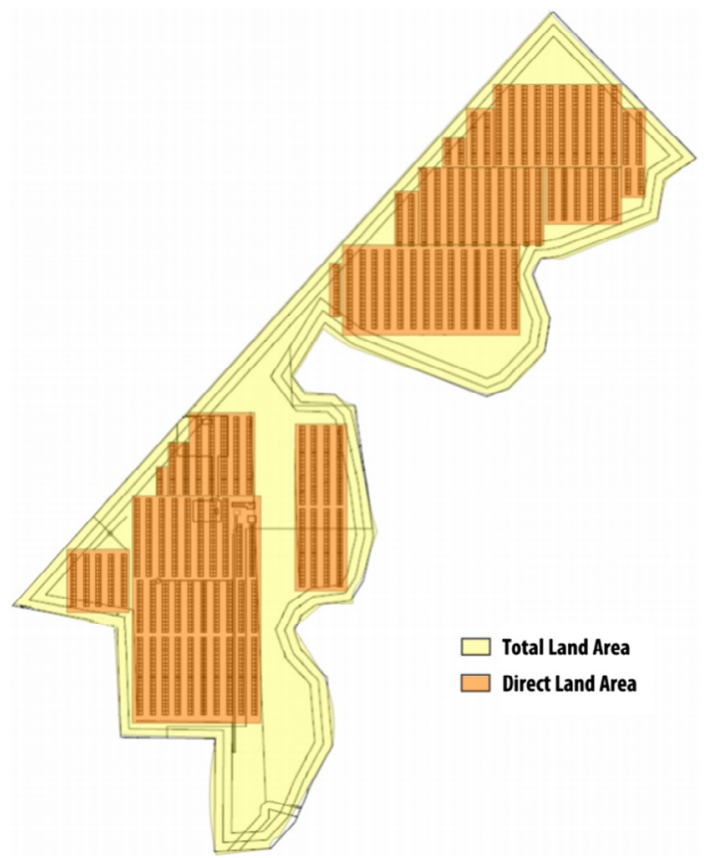

Fig. 5. Example of a photovoltaic plant blueprint, highlighting the total land use and the direct land use (source: Ong et al., 2013).

ing Conditions (STC), ${ }^{4}$ usually expressed in terms of watt-peak (Wp) or its multiples. For the purpose of this work, we estimate the nominal power $P_{\text {peak }}$ of the plants, via a simplified approach, i.e. as the ratio between the entire areal extension of the PV installation $A$ and a conversion factor:

$P_{\text {peak }}=\frac{A}{k}$

The area $A$ is the total land use, and includes the module area and the interrow spacing, some additional land occupied by access

\footnotetext{
${ }^{4}$ A photovoltaic modulus operates at STC if its temperature is $25^{\circ} \mathrm{C}$ and it is irradiated with a radiation of $1000 \mathrm{~W} / \mathrm{m} 2$ at Air Mass 1.5 (AM1.5) (International Standard IEC 60904-3). AM1.5 corresponds to the spectrum of the solar radiation after it has crossed 1.5 the thickness of the Earth's atmosphere, which is a typical situation occurring at medium latitudes.
} 


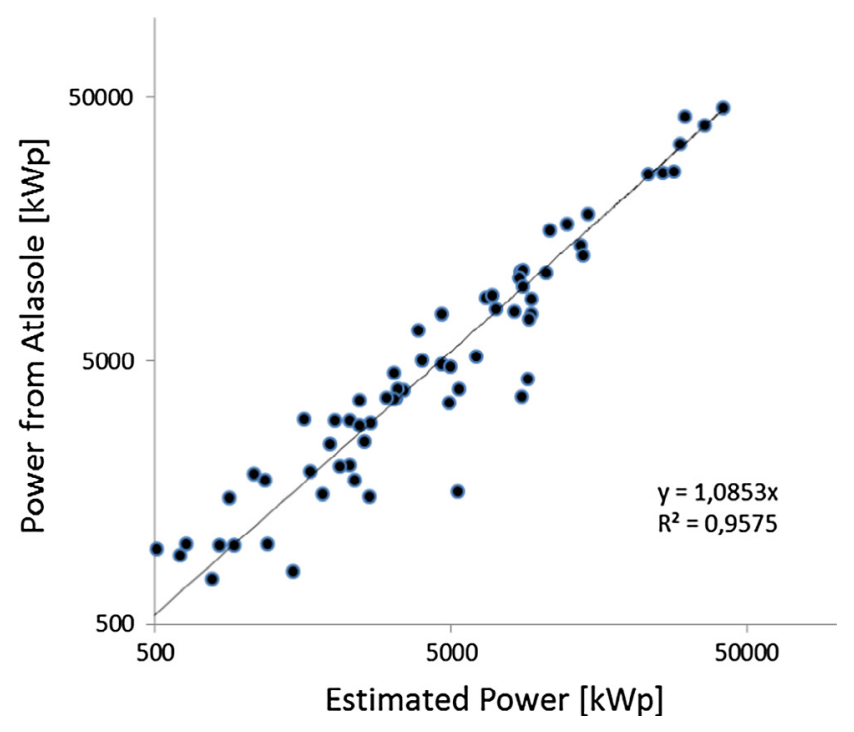

Fig. 6. Correlation between calculated (PV-GIS Lecce) and official data (AtlasoleGSE) of PV installed power at the municipality level. The scale is logarithmic.

roads and infrastructures, as well as some non-utilized land (see example in Fig. 5); the total land use is in fact the piece of data directly available from the GIS, as outlined in Section 6.1.

The factor $k$ represents the amount of total land per unit power installed and, based on a statistical study carried out on a large number of plants, has been calculated to be 35.2 (31.6-40.9) and 28.7 (23.5-32.8) square meters per installed kWp for tracking systems and for non-tracking systems, respectively; the values in parenthesis represent the parameter values at the 25th and 75th percentile of the plants considered in the study (Ong et al., 2013). The estimates $P_{\text {peak }}$ are calculated starting from PV-GIS
Lecce metadata, reporting the area of each PV farm (A) and typology of array (tracking or not).

Finally, we summarized by municipality the power estimates values $\left(P_{\text {peak }}\right)$ in order to compare them with GSE data, available only at this geographic level (Fig. 6).

\section{Results and discussion}

As described in Sections 6.1 and 6.2, we compared - at the municipality level - the PV installed power estimated from PVGIS Lecce map and the official GSE data (at the end of January 2016), only considering PV installations larger than $200 \mathrm{kWp}$. The comparison is shown in Fig. 6, where each data point corresponds to a single municipality. Overall, the graph shows a good correlation between the actual and estimated PV power for the entire range of solar farm sizes. However, it should be noted that in some cases a non-negligible discrepancy can be observed, which can be attributed to a number of factors. First, the approximation associated to the simplified approach described in Section 6.2 for the calculation of the installed power, and in particular the large uncertainty of the parameter $k$. This effect accounts for both over- and underestimations of the calculated installed PV power with respect to the officially reported one; especially in municipalities where only a few, large PV farms are present, quite large discrepancies may arise. On the other hand, some PV installations might be missed by the detection procedure, thus accounting for some of the underestimated values. Nevertheless, the value of the coefficient of determination $\left(R^{2}: 0.95\right)$ points out an excellent statistical significance of the correlation, when a large enough number of plants is considered.

In view of this result, we conclude that the PV-GIS Lecce map can be reliably utilized to estimate the spatial distribution of the installed PV farms (Fig. 7B). Overall, it includes 475 PV farms in more than $70 \%$ of municipalities (69 on the 97 ) of the Province of
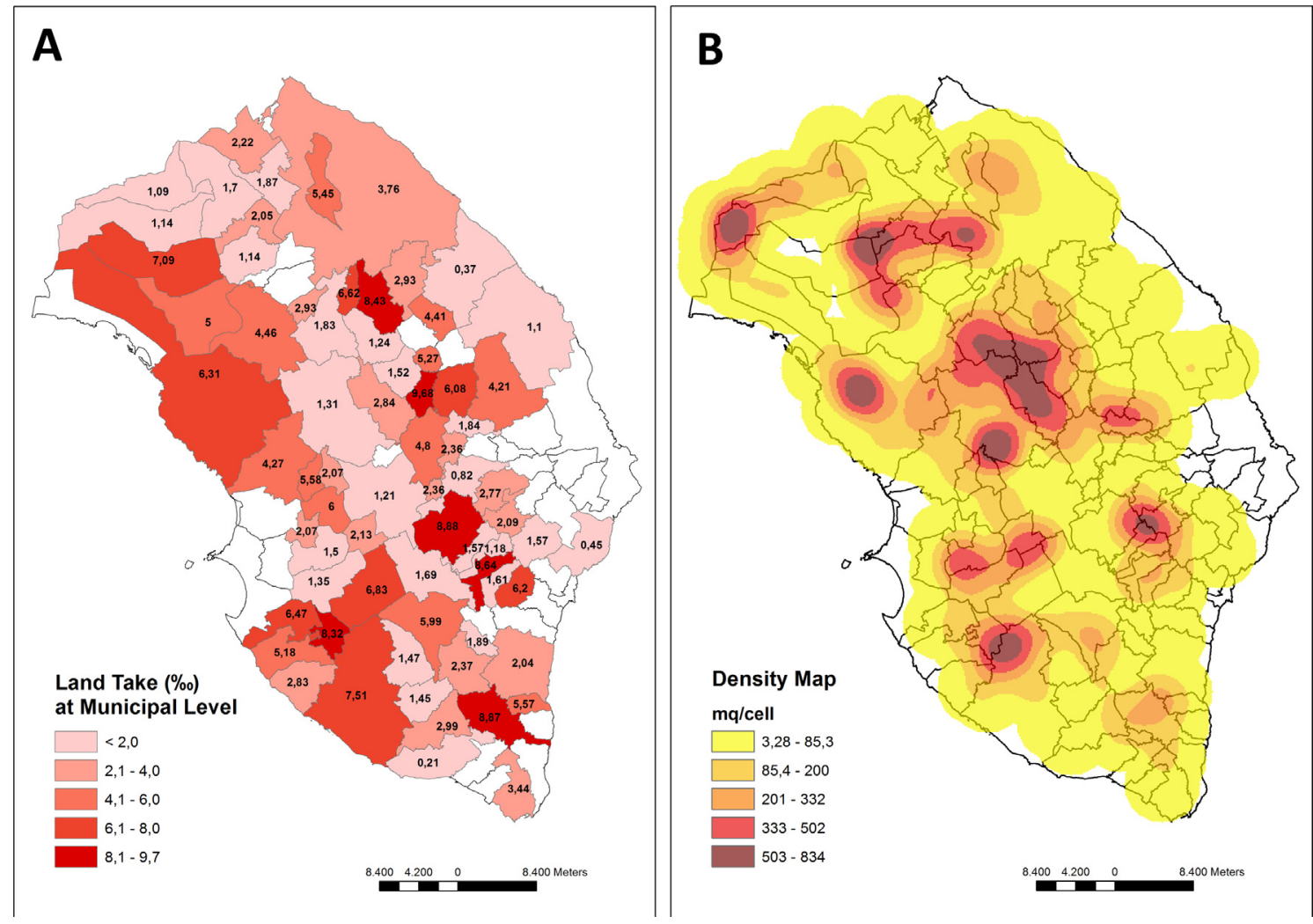

Fig. 7. A: Land take (\%o) at municipality level. B: Density Map of photovoltaic farms (KDE; bandwith: 4 km; Cell size: $150 \mathrm{~m}$ ). 


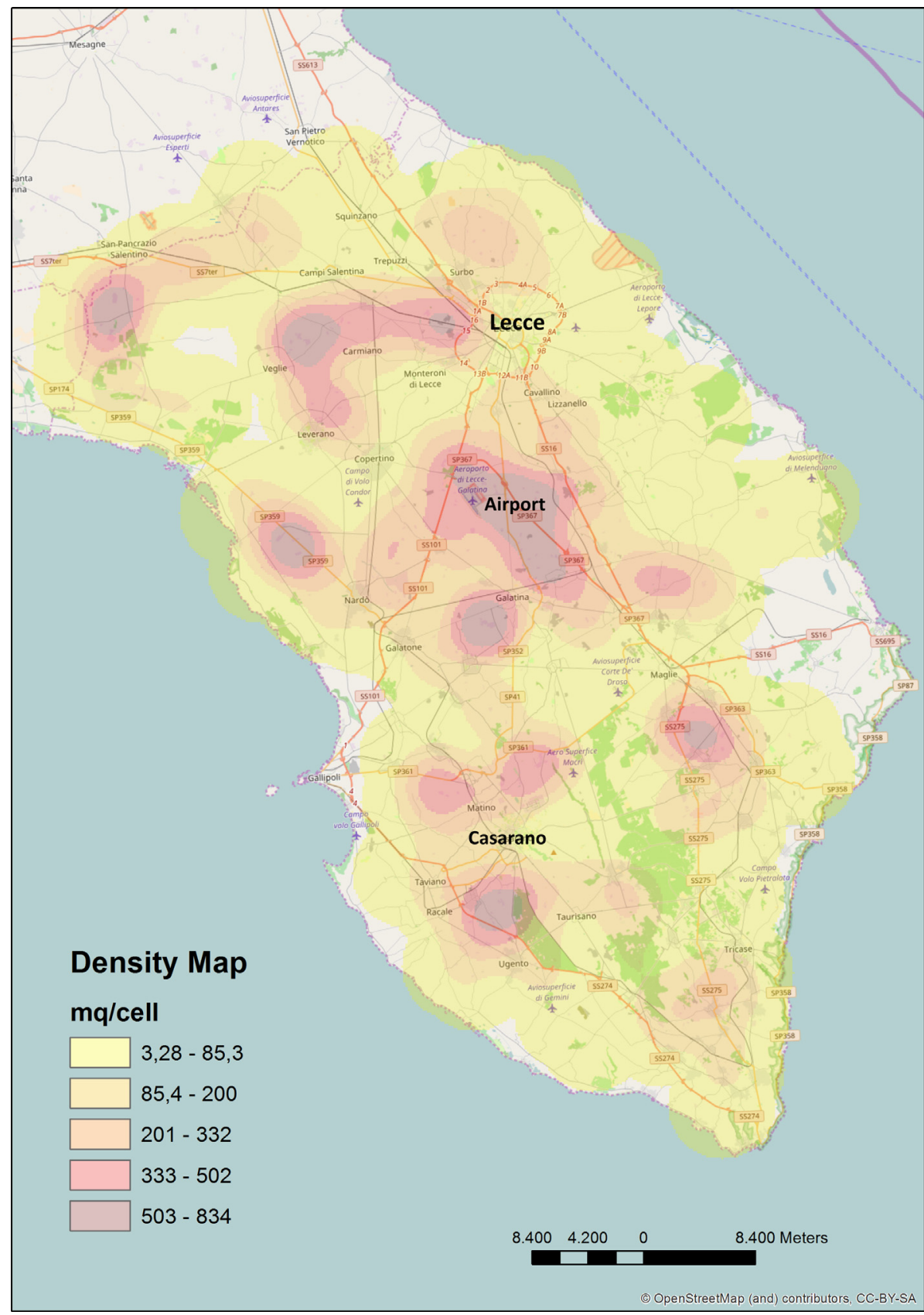

Fig. 8. Density Map of photovoltaic farms in Province of Lecce overlaid (in transparency) to the OpenStreetMap.

Lecce; in the remainder $30 \%$ only small plants were installed. The average size of each PV farm is about $2.8 \mathrm{Ha}$. Although almost half of the farms have an area of less than $2 \mathrm{Ha}$ (median value: $2.15 \mathrm{Ha}$ ), sometimes they cover quite large surfaces (maximum value: 20.7 $\mathrm{Ha}$ ). However, it should be noted that the VGI sometimes merged neighboring PV farms, so that the calculated number of PV farms is expected to be a slight underestimation. The total surface of PV farms within the study area is more than 1330 Ha, quite a significant number (almost 10\%) considering that the total surface covered by this technology at the national level is $13,786 \mathrm{Ha}$ (GSE, 2016).

The average value of installed power is $950 \mathrm{kWp}$; however, more than $90 \%$ of PV farms are smaller than $2 \mathrm{MWp}$. The total cumulated power of PV power stations in the study area is just over $450 \mathrm{MWp}$, consistent with GSE data when only considering plants above $200 \mathrm{kWp}$ (GSE, 2016), while the overall value includ- ing also the other typologies of plants (rooftop system and building integrated) is $677 \mathrm{MWp}$.

Regarding land take at the municipality level, we evaluated the loss in relative terms (as thousandths, \%o) compared to the total municipality area. The fraction of land take at municipality level is defined as:

$$
\begin{aligned}
& \text { Land take }_{\text {municipality }}(\% \circ) \\
& \qquad=\left(\sum \text { PV farm area } \text { municipality }_{\text {Municipality area }}\right) \times 1000
\end{aligned}
$$

The range of estimated land take across the entire set of municipalities is between $0.2 \%$ and $9.7 \%$, in all cases less than $1 \%$. Considering only municipalities with PV farms, the average of loss in soil is $3.6 \%$ : In absolute terms, it means a loss of about $20 \mathrm{Ha}$ per municipality - quite a marginal one, especially when considering the considerable contribution of PV to the electricity balance of 
Table 1

PV farms surface impacts (absolute and relative values) on the Land Cover Classes (level 3), resulting from CLC (2012).

\begin{tabular}{|c|c|c|c|c|c|}
\hline Land Cover Class (nomenclature) & $\begin{array}{l}\text { CLC } \\
\text { Code }\end{array}$ & $\begin{array}{l}\text { Land Cover Class } \\
\text { area }(\mathrm{Ha})\end{array}$ & $\begin{array}{l}\text { Percentage rate of } \\
\text { Land Cover Class (\%) }\end{array}$ & $\begin{array}{l}\text { Area of PV farms (Ha) for } \\
\text { Land Cover Class }\end{array}$ & $\begin{array}{l}\text { Thousandth rate PV farm for } \\
\text { Land Cover Class }(\% o)\end{array}$ \\
\hline Continuous urban fabric & 111 & 6896 & 2.5 & 3 & 0.4 \\
\hline Discontinuous urban fabric & 112 & 15,595 & 5.8 & 11 & 0.7 \\
\hline Industrial or commercial units & 121 & 1479 & 0.5 & 81 & 54.4 \\
\hline Mineral extraction sites & 131 & 1238 & 0.5 & 1 & 0.8 \\
\hline Construction sites & 133 & 25 & 0.0 & 12 & 490.7 \\
\hline Non-irrigated arable land & 211 & 67,119 & 24.8 & 652 & 9.7 \\
\hline Vineyards & 221 & 15,416 & 5.7 & 133 & 8.6 \\
\hline Olive groves & 223 & 101,628 & 37.6 & 122 & 1.2 \\
\hline Pastures & 231 & 3485 & 1.3 & 12 & 3.4 \\
\hline Annual crops associated with permanent crops & 241 & 3090 & 1.1 & 8 & 2.5 \\
\hline Complex cultivation patterns & 242 & 54,507 & 20.2 & 299 & 5.5 \\
\hline Total & & 270,477 & 100 & 1333 & 4.9 \\
\hline
\end{tabular}

the region, estimated as follows: in 2015 the gross electricity consumption in the Province of Lecce can be approximated to about $4300 \mathrm{GWh}$ (considering the average Italian consumption and a population of 804,000), therefore the $973.9 \mathrm{GWh}$ produced by PV (GSE, 2016) represent well over $20 \%$ of the local electricity need.

Concerning to the geographical distribution of PV farms within the Province of Lecce, we created the land take map at the municipality level (Fig. 7A) and the heatmap of PV farms (Fig. 7B). In the first, we classified municipalities on the basis of soil loss, while in the second we consider density values. ${ }^{5}$ Even if from a different perspective, both clearly show several interesting geographical topics. First, the more touristic areas (the East coast and the South of the Province) are less affected by land take due to the PV farms. On the other hand, peaks of density (maximum value: $837 \mathrm{~m}^{2} /$ cell) are found in the north-centre area and along the west coast: geomorphology, demographic, infrastructure, and industrial districts may influence this spatial distribution. In fact, by comparing the geomorphology map of digital terrain model (Fig. 2B) with the density map (Fig. 7B), one may observed as plane landscape (i.e., the Tavoliere salentino) is usually selected for the installation of PV farms.

However, as pointed out in section 6.1, the KDE procedure highlights spatial trends (Fig. 8). So, for example, it is possible to observe the 'PV farms sprawl' in the southerly and east directions with respect to the main urban area, Lecce (close to the town - but outside its ring road - and in proximity of the airport). A similar situation can be observed in proximity of Casarano, an important industrial district for clothing, centrally positioned between three high PV concentration areas. Urban and industrial systems are obviously characterized by high consumption of energy, so the proximity of electrical power plants can be in principle rather beneficial.

Table 1 reports the PV farms impact on the Land Cover Classes (level 3), resulting from CLC 2012 (cf. Section 5). The third and fourth columns refer, for each Land Cover Classes in the Province of Lecce, to the area occupied by PV farms, in absolute and relative terms. Agricultural landscape classes are the most significant ones: olive groves (37.6\%), non-irrigated arable land (almost 25\%) and complex cultivation patterns $(20.2 \%$ ) cover over the $80 \%$ of the Province of Lecce (total over than 270,000 $\mathrm{Ha}$ ).

One can observe that PV farms greatly overlap with construction sites ( $12 \mathrm{Ha}$ of 25 , almost $50 \%$ ), most likely because this class often refers to PV plants under construction. The incidence of PV farms is also quite significant within industrial or commercial units (almost of 5.5\% of the surface of this class): utility-scale systems prices are likely to drive installation of PV farms in proximity of secondary or tertiary activities (Goodrich et al., 2012; Agostinelli

\footnotetext{
${ }^{5}$ As regard the classification algorithm, in the first case we applied equal interval, in the second natural breaks (Michell, 1999).
}

et al., 2015). With regard to agricultural landscape, in relative terms PV farms do not have a great incidence. The most significant impact is on non-irrigated arable land and on vineyards, almost $1 \%$ (in real terms, about $650 \mathrm{Ha}$ ) and $0.86 \%$ (133 Ha), respectively: the PV farms could represent a new deal for farmers in a crisis period, mainly for cereal crops (Section 4; ISTAT, 2011). On the other hand, the incidence on the most significant class, i.e. olive groves, is rather marginal.

\section{Conclusions}

Conclusions about this work can be drawn from two different standpoints. On the one hand, our work points out some significant aspects of land use associated with PV installations. A first result is the spatial distribution of the PV installations on the territory, here represented as a map of land take or as density map, showing that the inland areas of the Tavoliere Salentino are preferred, while the coastal, touristic areas have only marginally been involved in the recent massive development of PV. Another result is the classification of the soil consumed by PV installations according to Land Cover Classes, which is a piece of information that is not provided by GSE. The key observation here is that the vast majority of the land used for PV farms (49\% of it) is classified as non-irrigated arable land, i.e. soil that is currently not being cultivated; of this land, only less than $1 \%$ has been occupied by PV installations. Another $42 \%$ of the land dedicated to PV coexists with some other cultivation (complex cultivation patterns, vineyards, olive groves); however, this involves only about $0.3 \%$ of the area occupied by such cultivations. About 6\% of PV installations (in terms of surface area) has been installed on or near industrial or commercial units, with no impact on agriculture and cultivations. The remainder of the land occupied by PV is essentially negligible both in terms of absolute surface area $(<3 \%)$, and in terms of impact on each of the remaining land cover classes. In conclusion, the analysis shows how land take by PV farms is quite marginal, even in a region such as the Province of Lecce - i.e. the area with the highest incidence of PV production in one of the Countries with the highest density of PV production per capita and per surface area. This is even more true considering the strong contribution of PV to the local electricity need (over 20\%).

The second contribution of this work is of methodological nature. This study demonstrates the potential of a participative cartography-based GIS for becoming a quick, reliable tool for collecting, displaying and analyzing data, on a variety of scales, about PV penetration and its relationship with the geographical characteristics of a territory. Important parameters associated with large-scale PV generators can be assessed: the annual energy production, the installed power - which, as we demonstrated, can be 
estimated to a very good accuracy - and land take. For the latter, in particular, immediate meaningful conclusions can be drawn by comparison with other GIS or thanks to other cartographic tools, such as for the examples shown in this work - land consumption categorized by land cover class, or the density map of installations. This methodology is therefore a potentially useful forecasting tool or an aid for planning and decision-making. In general, a largescale map of PV farms could be an opportunity to study land transformation or potential land use conflicts among existing landbased economies and ecosystem services (Calvert and Mabee, 2015).

The base methodology only requires access to VGI-platforms, such as the one used for this work (OSM), and all the analyses have been carried out by using solely freely available data. For this reason, this methodology could be particularly useful when a quick assessment is required, such as in the early stages of territorial planning or for rough analyses, or when systematic monitoring and detailed data sources are scarce. This latter might be the case when rapid expansion of PV is occurring, or in many developing economies - where sometimes univocal and reliable data sources are lacking, yet GPS equipped telephones are nevertheless ubiquitous. In such cases, the lack of a culture of data sharing, rather than the digital divide, might be more of a factor in undermining the reliability and applicability of this methodology. Conversely, we point out the case of the United States of America, where on the contrary the culture of participative tools in general is quite diffused and participative cartography in particular is quite developed, especially in rural areas; the USA are now going through a quite rapid expansion of PV, and for the reasons mentioned above, the use of methodologies such as the one outlined in this work might be particularly reliable for forecasting, planning, and analyzing the deployment of PV at all territorial levels. Another merit of the methodology outlined here is the fact that it is based on open cartographic data, which are updated quite often - usually with a much higher frequency than statistical reports and similar data sources. This ensures up-to-date results, a key factor in analyzing and planning highly dynamic and fast-changing phenomena such as the deployment of PV.

Finally, the observations we made in this work are only part of the potential use of this methodology, and should be considered as prototypes and starting points for identifying more possible correlations between land use by PV and other social and geographical aspects of the territory - such as the preferred land conformation, local policies, local social habits, tourism, etc.

\section{Authors contribution}

This paper is a result of the full collaboration of all the authors. However G. Mauro wrote paragraphs 1, 2, 4, 5, 6.1 and 7, while V. Lughi wrote paragraphs 3, 6.2 and 8.

\section{References}

Agostinelli, G., Bardouille, P., Gassner, K., Govindarajalu, C., Jones, R., Mandal, H., Merle-Beral, E., Miller, A., Moreno, A., Payeras, J., Tait, B., Levin, J., Kellenberg, J., 2015. Utility-Scale Solar Photovoltaic Power Plants. International Finance Corporation (IFC), Washington. DC. Available on: <https://www.ifc.org/wps/ wcm/connect/f05d3e00498e0841 bb6fbbe54d141794/IFC+Solar+Report_Web+ 08+05.pdf?MOD=AJPERES $>$ (accessed on October 5, 2016)

Bennet, J., 2010. OpenStreetMap, Be Your Own Cartographer. PACKT Publishing, Birmingham.

Borrough, P.A., 1990. Principles of Geographical Information Systems for Land Resources Assessment. Oxford University Press, UK.

Borruso, G., 2008. Network density estimation: a GIS approach for analysing point patterns in a network space. Transact. GIS 12 (3), 377-402.

Brian, A.J., Kotaro, I., 2016. Integrating OpenStreetMap crowdsourced data and Landsat time-series imagery for rapid land use/land cover (LULC) mapping: Case study of the Laguna de Bay area of the Philippines. Appl. Geogr. 67, 140149.
Calvert, K., Mabee, W., 2015. More solar farms or more bioenergy crops? Mapping and assessing potential land-use conflicts among renewable energy technologies in eastern Ontario, Canada. Appl. Geogr. 56, 209-221.

Chainey, S., Ratcliffe, J., 2013. GIS and Crime Mapping. John Wiley \& Sons, Chichester, UK.

Chiabrando, R., Fabrizio, E., Garnero, G., 2009. The territorial and landscape impacts of photovoltaic systems: definition of impacts and assessment of the glare risk. Renew. Sustain. Energy Rev. 13, 2441-2451.

Cipeluch, B., Jacob, B., Winstanley, R., 2010. Comparison of the Accuracy of OpenStreetMap for Ireland With Google Maps and Bing Maps. Proceedings of the Ninth International Symposium on Spatial Accuracy Assessment in Natural Resources and Environmental Sciences. University of Leicester, UK.

Choi, Y., Rayl, J., Tammineedi, C., Brownson, J.R.S., 2011. PV Analyst: coupling ArcGIS with TRNSYS to assess distributed photovoltaic potential in urban areas. Sol. Energy 85, 2924-2939.

Coiante, D. 2008. Limiti e prospettive delle fonti rinnovabili in Italia. Economia delle fonti di energia e dell'ambiente 2, FrancoAngeli, 163-179 (in Italian).

Colmenar-Santos, A., Campíñez-Romero, S., Pérez-Molina, C., Mur-Pérez, F., 2016. An assessment of photovoltaic potential in shopping centres. Sol. Energy 135, 662-673.

Cressie, N.A.C., Wikle, C.K., 2011. Statistics for Spatio-Temporal Data. Wiley, Hoboken, N.J.

Danese, M., Lazzari, M., Murgante, B., 2008. Kernel Density Estimation Methods for a Geostatistical Approach in Seismic Risk Analysis: The Case Study of Potenza Hilltop Town (Southern Italy). In: Gervasi, O. (Ed.), ICCSA 2008, Part I, LNCS 5072. Springer-Verlag, Berlin, Heidelberg.

Delmelle, E., Dony, C., Casas, I., Jia, M., Tang, W., 2014. Visualizing the impact of space-time uncertainties on dengue fever patterns. Int. J. Geograph. Inform. Sci. 28 (5), 1107-1127.

Dinesh, H., Pearce, J.M., 2016. The potential of agrivoltaic systems. Renew. Sustain. Energy Rev. 54, 299-308.

Energy Strategy (ES) Group, 2014. Solar Energy Report. Politecnico di Milano, Milano. Available on: <http://www.energystrategy.it/report.html> (accessed on September 30, 2016).

European Environment Agency (EEA), 2008. Land take. Copenhagen, Denmark. Available on: <http://www.eea.europa.eu/data-and-maps/indicators/land-take2 /assessment> (accessed on October 3, 2016).

European Environment Agency (EEA), 1995. CORINE Land Cover. Available on line: <http://www.eea.europa.eu/publications/COR0-landcover> (accessed on October 12, 2016).

Frascarelli, A., Ciliberti, S., 2011. La diffusione del fotovoltaico in Italia e l'impatto sull'agricoltura. Agriregionieuropa, anno 7, 24 (in Italian).

Gestore Servizi Elettrici (GSE), 2016. Rapporto statistico 2015. Solare fotovoltaico. Roma, Italia. Available at: <http://www.gse.it/it/Statistiche/RapportiStatistici/ Pagine/default.aspx> (accessed on October 20, 2016) (in Italian).

Gestore Servizi Elettrici (GSE), 2017. Energia da Fonti Rinnovabili in Italia, Anno 2015. Roma, Italia. Available on: <http://www gse.it/it/Statistiche/ RapportiStatistici/Pagine/default.aspx> (accessed on March 25, 2017) (in Italian).

Goodchild, M.F., 2007. Citizen as sensors: the world of volunteered geography. GeoJournal 69 (4), 211-221.

Goodchild, M.F., Glennon, J.A., 2010. Crowdsourcing geographic information for disaster response: a research frontier. Int. J. Digital Earth 3 (3), 231-241.

Goodrich, A., James, T., Woodhouse, M., 2012. Residential, Commercial, and UtilityScale Photovoltaic (PV) System Prices in the United States: Current Drivers and Cost-Reduction Opportunities. Technical Report NREL/TP-6A20-53347. Available on: < http://www.nrel.gov/docs/fy12osti/53347.pdf> (accessed on September 28, 2016).

Hart, T., Zandbergen, P., 2014. Kernel density estimation and hotspot mapping: examining the influence of interpolation method, grid cell size, and bandwidth on crime forecasting. Policing: Int. J. Police Strategies Manage. 37 (2), 305-323.

International Energy Agency (IEA), 2016. PhotoVoltaic Power System (PVPS) Annual Report 2015. Fribourg, Switzerland. Available on: <www.iea-pvps.org/index. php?id=3\&eID=dam_frontend_push\&docID=3195> (accessed on August 25, 2016)

Italian National Institute for Environmental Protection and Research (ISPRA), 2014. Soil consumption in Italy. Reports, 195/2014, Roma.

Italian National Institute of Statistics (ISTAT), 2011. 6 Agricultural Census. Roma.

Kounadi, O., 2009. Assessing the quality of OpenStreetMap data MSc Geographical Information Science. University College of London, Department of Civil, Environmental and Geomatic Engineering, London.

Lillesand, T.M., Kiefer, R.W., 2000. Remote Sensing and Image Interpretation. Wiley, New York.

Mauro, G. 2011. La rappresentazione delle città di confine nella cartografia libera di OpenStreetMap: il caso di Gorizia-Nova Gorica. Bollettino dell'Associazione Italiana di Cartografia 143, 349-364. Available on: <http://hdl.handle.net/ 10077/11901> (accessed on June 20, 2016) (In Italian)

Michell, A., 1999. The ESRI Guide to GIS Analysis: Geographic patterns \& relationships, vol. I, ESRI Press.

Neis, P., Zielstra, D., 2014. Recent developments and future trends in volunteered geographic information research: the case of OpenStreetMap. Future Internet 6, 76-106.

Observ'Er, 2015. The State of Renewable Energy in Europe. 15th EurObservEr Report. Observ'Er, Paris. Available on <http://www.energies-renouvelables.org> (accessed on March 30, 2017). 
444

G. Mauro, V. Lughi/Solar Energy 155 (2017) 434-444

Ong, S., Campbell, C., Denholm, P., Margolis, R., Heath, G., 2013. Land-Use Requirements for Solar Power Plants in the United States. Technical Report NREL/TP-6A20-56290. Available on: <http://www.nrel.gov/docs/fy13osti/ 56290.pdf> (accessed on September 8, 2016).

Pacesila, M., Burcea, S.G., Colesca, S.E., 2016. Analysis of renewable energies in European Union. Renew. Sustain. Energy Rev. 56, 156-170.

Pauli, F., Sulligoi, G., Lughi, V., Massi Pavan, A., 2015. Grid parity in the Italian domestic PV market a sensitivity analysis. Int. Conf. Renew. Energy Res. Appl. (ICRERA), 1477-1480 (2015).

Peterson, M.P., 2014. Mapping in the Cloud. Guilford Press, New York.

Ramm, F., Topf, J., Chilton, S., 2011. OpenStreetMap, Using and Enhancing the Free Map of the World. UIT, Cambridge.

Ribeiro, A., Fonte, C.C., 2015. A methodology for assessing OpenStreetMap of coverage for purposes of land cover mapping. ISPRS Annals of the Photogrammetry, Remote Sensing and Spatial Information Sciences, Volume II-3/W5, 2015 ISPRS Geospatial Week 2015, 28 Sep - 03 Oct 2015, La Grande Motte, France. Available on: <http://www.isprs-ann-photogramm-remotesens-spatial-inf-sci.net/II-3-W5/297/2015/isprsannals-II-3-W5-297-2015.pdf> (accessed on July 8, 2016).

Salvador, S., 2010. Cartografia Regione Autonoma Friuli Venezia Giulia e OpenStreetMap: risultati di un anno di collaborazione. Giornate triestine degli utenti gvSIG, Regione Friuli Venezia Giulia, Trieste. Available on line: <http:// salvaste.altervista.org/files/articolo.pdf> (accessed on June 25, 2016) (In Italian).

Sestini, A., 1963. Il paesaggio. Conosci l'Italia, vol. II, Touring Club Italiano, Milano, 169-172. (In Italian).
Silverman, B.W., 1986. Density Estimation for Statistics and Data Analysis. Chapman \& Hall, London.

Spalatro, M., Nicoletti, G.M., 2014. Scarsi obiettivi per le rinnovabili elettriche. Energia 4, 42-46.

Sui, D., Goodchild, M., Elwood, S., 2013. Volunteered Geographic Information, the Exaflood, and the Growing Digital Divide. In: Sui, D., Elwood, S., Goodchild, M. (Eds.), Crowdsourcing Geographic Knowledge. Voluntereed Geographic Information (VGI) in Theory and Practice. Springer, pp. 1-12.

SVIMEZ-SRM, 2011. Energie rinnovabili e territorio. Scenari economici, analisi del territorio e finanza per lo sviluppo. Giannini editore, Napoli (In Italian).

Torres-Sibille, A., Cloquell-Ballester, V., Cloquell-Ballester, V., Ramirez, M., 2009. Aesthetic impact assessment of solar power plants: an objective and subjective approach. Renew. Sustain. Energy Rev. 13 (5), 986-999.

Tsoutsos, T., Frantzeskaki, N., Gekas, V., 2005. Environmental impacts from the solar energy technologies. Energy Policy 33, 289-296.

Viana, T.S., Rüther, R., Martins, F.R., Pereira, E.B., 2011. Assessing the potential of concentrating solar photovoltaic generation in Brazil with satellite-derived direct normal irradiation. Sol. Energy 85, 486-495.

Wüstenhagen, R., Wolsink, M., Bürer, M., 2007. Social acceptance of renewable energy innovation: an introduction to the concept. Energy Policy 35, 26832691.

Zieltra, D., Hocmair, H.H., 2011. Digital Street Data: free versus proprietary. GIM Int. 25, 29-33.

Zoellner, J., Schweizer-Ries, P., Wemheuer, C., 2008. Public acceptance of renewable energies: results from case studies in Germany. Energy Policy 36, 4136-4141. 